\title{
Silencio a través: analogías musicales en la obra de Sergio Rubio, Silencio
}

\section{Raquel Jurado Díaz}

\section{(2) OpenEdition}

1 Journals

Edición electrónica

URL: https://journals.openedition.org/cher/1051

DOI: $10.4000 /$ cher. 1051

ISSN: 2803-5992

Editor

Presses universitaires de Strasbourg

Edición impresa

Fecha de publicación: 11 julio 2019

Paginación: 27-37

ISBN: 979-10-344-0046-1

ISSN: $1968-035 X$

Referencia electrónica

Raquel Jurado Díaz, «Silencio a través: analogías musicales en la obra de Sergio Rubio, Silencio», reCHERches [En línea], 22 | 2019, Publicado el 07 octubre 2021, consultado el 20 noviembre 2021 URL: http://journals.openedition.org/cher/1051 ; DOI: https://doi.org/10.4000/cher.1051 


\title{
Silencio a través: analogías musicales en la obra de Sergio Rubio, Silencio
}

\author{
Raquel JuRAdo DíaZ1
}

\begin{abstract}
$\mathrm{D}$ urante un concierto en homenaje a los compositores de la llamada escuela de New York ${ }^{2}$ tuve la ocasión de interpretar al piano Intermission 6 de Morton Feldman. La partitura -para uno o dos pianos- consta de 15 "eventos" sonoros que oscilan desde notas aisladas a complejos acordes. Feldman especifica que los mismos se pueden interpretar en el orden que se desee. La única instrucción fijada es que se interpreten en un nivel de intensidad moderado y que no se toque el siguiente acorde o nota hasta que se haya extinguido el anterior o sea imperceptible. En nuestra performance habíamos previsto que las obras elegidas de los compositores de New York se interpretarían de forma simultánea, solapándose una con otra, de manera que mientras se leía Conferencia sobre algo de John Cage, se comenzaría a interpretar Stones de Christian Wolff. Tras un tiempo más o menos fijado pero no preciso se iniciaría Sticks, también de Wolff, y aproximadamente hacia la mitad de la pieza de Cage, comenzaría Intermission 6 de Feldman. Cuando llegó el momento me levanté de mi asiento en el patio de butacas, subí al escenario y me dirigí hacia el piano de cola. Sin prisa me senté y coloqué la partitura, mientras escuchaba la increíble resultante sonora de las otras tres piezas que ya se estaban interpretando. En mi mente comenzaron a resonar el abanico de acordes de la pieza de Feldman, dispuestos a ser elegidos para ser sonados y mostrados "como nunca antes", únicos, especiales, sin dirigirse hacia ningún otro sonido y sin venir de ningún otro, solo rodeados de ese particular espacio sonoro que se estaba generando en ese preciso momento e imposible de repetirse jamás.

Frente al piano, pensaba igualmente cuál sería el momento “idóneo" para hacer sonar el acorde elegido y, paradójicamente, nunca me parecía encontrar

1 Raquel Jurado Díaz, Universidad de Córdoba (España)

2 En New York, hacia mitad del s. XX se produjo un interesante y duradero encuentro entre los pintores vinculados con el expresionismo abstracto y compositores inspirados por este movimiento, entre ellos John Cage, Morton Feldman, Earle Brown y Christian Wolff.
\end{abstract}


el instante adecuado. Mi interpretación de Intermission 6 fue sobre todo, silenciosa. Los acordes y notas sueltas emergían casi de la nada, estructurando, casi interrumpiendo de alguna manera el lienzo en blanco del "silencio" en el que transcurría. Hacia el cuarto o quinto evento sonoro decidí incluir en mi interpretación la acción de abrir y cerrar una caja de cartón que estaba sobre el piano. Antes de sonar un acorde abría la caja "para liberar el sonido", dejar que los sonidos "sean" ellos mismos3. Cuando estimaba que el sonido se había extinguido cerraba de nuevo la caja, para volverla a abrir antes de cada nuevo evento sonoro. No podría decir exactamente cuándo acabó la pieza. ¿Acabó cuando se extinguió el último acorde? ¿O finalizó después del largo silencio que transcurrió hasta que me levanté del piano? Entonces, ¿cuándo comenzó realmente? ¿Empezó cuando sonó el primer acorde o cuando, en silencio escuchaba y decidía en qué orden se sucederían los eventos? O quizá la pieza empezó cuando decidí levantarme de mi butaca, subir al escenario, quitarme los zapatos y desplazarme descalza hacia el piano. De igual manera surgen otros interrogantes: ¿es la pieza una sucesión de 15 acordes? ¿O los acordes más los silencios entre ellos? ¿Es el silencio un material musical? ¿En qué proporción habría que articular ambos materiales?

La reflexión sobre el silencio en música ha sido muy intensa durante el siglo XX, alcanzando su punto más álgido y controvertido a raíz de la afirmación del compositor americano John Cage de que el silencio absoluto no existe o al menos, es imposible escucharlo. Cage llega a esta conclusión tras su conocida experiencia en la cámara anecoica de la Universidad de Harvard. Al salir de esta habitación silenciosa Cage comentó a los técnicos que había escuchado un sonido agudo y otro grave durante todo el tiempo, a lo que respondieron que se trataba de los sonidos de sus sistemas nervioso y circulatorio. Cage concluye entonces que es imposible escuchar el silencio absoluto. Sin embargo, lejos de marginarlo le asignará la categoría de material musical "sonoro" y propondrá una nueva escucha atenta hacia el mismo. Será en 1952 cuando, animado por la muestra de White Paintings de su amigo el artista Robert Rauschenberg, situará esta escucha en primer plano utilizando el silencio como único material en su conocida pieza 4'33"4.

La propuesta de Cage consiste en escuchar el silencio con la misma atención que le otorgamos a los sonidos. Los materiales musicales son, por tanto, sonido y silencio, y componer consistirá en articular ambos.

3 Según Pardo Salgado, "dejar ser el sonido" implica en Cage una desvinculación del mismo de la semántica que le da sentido, por lo cual se hace necesaria una nueva escucha emancipada de la tradición.

4 La partitura consiste en un texto en el que se lee la palabra Tacet (silencio) en cada uno de los movimientos en los que se articula la pieza. El estreno de 4'33" corrió a cargo de David Tudor, en 1952. Para separar las tres secciones en que se estructura la pieza, Tudor decidió realizar la acción de abrir y cerrar la tapa del piano entre cada movimiento, permaneciendo en silencio durante el resto de la interpretación. 
Del mismo modo, en la obra de Sergio Rubio se articulan sonido y silencio, al menos, silencio en sentido figurado. Los personajes de Silencio, los anónimos Él y Ella, son una pareja en declive que, incapaces de afrontar su situación, se dirigen mutuos reproches en silencio. Estos monólogos del pensamiento -los que contienen las verdades que no se dicen- resuenan silenciosamente durante la cena en un restaurante, siendo interrumpidos únicamente por breves diálogos "sonoros" irrelevantes e impersonales.

Se producen pues diferentes planos sonoros: el contenido/material relevante se articula en el silencio del pensamiento, por lo que, de manera paradójica, y a pesar de que se nos muestra silencioso, ocupa un primer plano ya que "representa" el "tema principal". Sin embargo, es el material en este caso "sonoro" el que, aunque es audible en forma de diálogo o dúo -casi siempre interrumpiendo el discurso del pensamiento-, resulta totalmente irrelevante ocupando así un plano secundario. De esta manera, siguiendo a Cage, sonido y silencio constituyen los materiales básicos de Silencio, los cuales, mostrados y combinados de diferentes maneras, estructuran la pieza dotándola de ritmos, cambios de tempo y texturas muy diversas.

Silencio, de Sergio Rubio, consta de seis escenas, la mayor parte de ellas estructuradas alternando estos "silencios sonoros" del pensamiento -es decir, en teoría solo audibles en la mente del personaje que los emite- con diálogos audibles. Encontramos entonces un símil con la anécdota anterior ya que el texto comienza con un monólogo "silencioso" de Él. Pero igualmente podría comenzar en un silencio anterior, invadido por el sonido lejano de la lluvia a la que alude el personaje. $\mathrm{O}$ el silencio del restaurante. $\mathrm{O}$ podría comenzar con el silencio de Ella, en su solitaria espera. ¿Y cuándo acaba? ¿en la última frase de Ella o en el silencio que, como se nos muestra obvio, seguirá inevitablemente a continuación? Los silencios se suceden, se solapan, se interpenetran -diría John Cage-, dando lugar a diferentes y significativas calidades de silencio.

En este sentido, encontramos otra analogía en la pieza Waiting (1952), de John Cage. Al igual que ocurre en Silencio, la pieza comienza y acaba silenciosamente. El inicio de la partitura de Waiting consiste en varios compases de silencio agrupados según una secuencia numérica, estructurando de alguna manera este particular comienzo silencioso. De igual manera el final de la pieza consiste en cuatro compases de silencio estructurados como 1+3. En el transcurso de la pieza se van sucediendo fragmentos sonoros que, alternados con otros en silencio, parecen emerger de la nada habitando brevemente el "silencio" que enmarca la pieza. Estos fragmentos sonoros pierden interés en la medida en que, por su simpleza y carácter repetitivo, parecen no tener nada que decir o que aportar. De igual manera, los diálogos que interrumpen los monólogos de los personajes de Silencio no contienen un material significativo -en cuanto que las "verdades" se dicen en silencio-, sin embargo sí que cumplen un papel estructural, al igual que ocurre en Waiting. 
En Silencio de Sergio Rubio, los monólogos silenciosos de los personajes se nos muestran sonoros, en primer plano, siguiendo el tempo propio de los pensamientos de cada uno de los "intérpretes", generando una compleja textura contrapuntística. Estos "compases" silenciosos cobran intensidad, timbre, altura, velocidad y textura al ritmo que marca el texto, pasando a ser los verdaderos contenedores del mensaje relevante. De esta manera, los microdiálogos, que, siguiendo nuestra analogía se corresponderían con las intervenciones "sonoras" acústicamente hablando, pasan a un segundo plano, casi como un ruido de fondo, aun sin dejar de ser parte estructural de la pieza.

Como escribe Tom Johnson, en un intento de identificar los diferentes enfoques del minimalismo en música:

Uno puede retardar la música hasta dos o tres notas por minuto, ..., o bien uno puede eliminar incluso esto y conseguir una música que consista en un $90 \%$ o en un $95 \%$ de silencio. O puede ir más allá y hacer que sea una música que sea silencio en un 100\% (AA.VV 2001: 129).

Este sería el caso de 4'33".

En el texto que nos ocupa, tras hacer un recuento de las palabras "audibles" -las que constituyen un diálogo- y las "no audibles" de la obra -aquellas que los personajes se dicen en su monólogo interior-, podríamos concluir, musical y metafóricamente hablando, que Silencio consiste en un 95\% de silencio y solo un $5 \%$ de sonido.

Deteniéndonos en la primera escena de Silencio, "De beber...”, y desde nuestro enfoque musical, cabría escuchar los monólogos de Él y Ella simultáneamente, superponiendo ambos textos. Los personajes comenzarían a lanzar sus monólogos silenciosos en el momento en que se encuentran en el restaurante generando de esta manera una textura verbal contrapuntística. Siguiendo esta idea, casualmente -o no- encontramos que el número de palabras silenciosas de Él y Ella coinciden: 430. ¿Coincidencia o máxima precisión compositiva? ¿Se podría estructurar temporalmente Silencio para resaltar estos aspectos a la manera de una composición musical?

En esta línea planteamos otra analogía con una de las técnicas compositivas de John Cage. Nos referimos a lo que él llama "paréntesis o contenedores temporales", empleados sobre todo en las llamadas "number pieces" -a las que dedicó los últimos años de su vida-. El título de las piezas -siempre un númerohace alusión al número de intérpretes. Estas piezas consisten, en su mayoría, en largas notas simples que emergen y desaparecen rodeadas de silencio. Cage establece un marco temporal flexible, a modo de lienzo en blanco, marcando un inicio y un final aproximado dentro del cual tendrá lugar el evento sonoro a decisión del intérprete. Cuando en la pieza intervienen varios músicos las combinaciones, superposiciones, texturas, etc., surgen espontáneamente ya que cada intérprete desconoce en qué momento intervendrán los demás, resultando cada interpretación de la misma pieza diferente a cualquier otra. 
En la obra de Rubio cada personaje interpreta la partitura de su pensamiento, que fluye en silenciosos paréntesis temporales solo interrumpidos por microdiálogos. Cabría entonces imaginar cómo las superposiciones aleatorias de estos textos generarían complejas polifonías “inaudibles” dentro de unos marcos de tiempo más o menos fijados. ¿Podríamos entonces transcribir la partitura el texto de Rubio? No sería nada nuevo ya que el propio John Cage utiliza estos contenedores temporales para articular el texto de su Conferencia sobre nada como si fuera una composición musical.

Ahondando en la reflexión sobre el concepto "silencio", en el texto de Rubio podemos escuchar multiplicidad de silencios "audibles" articulados en diferentes planos:

Silencio de fondo: la lluvia a la que Él hace alusión al llegar está presente pero no la llegamos a escuchar con claridad ya que ocurre fuera del recinto: "Perdona el retraso, fuera está lloviendo...” (Rubio 2002: 11a)

Silencio "arquitectónico": el espacio sonoro en que se produce el sonido/ ruido/silencio es fundamental ya que condiciona la percepción de todas sus cualidades y por tanto constituye una variable muy significativa. En el texto de Rubio se hace referencia a él en la tercera escena: “... ¿por qué siempre este lugar? Este espacio enorme, gigantesco como un palacio a oscuras. ¿Por qué siempre este silencio?” (Ibídem: 13a)

Silencios-estratos: el autor inserta silencios dentro de los propios monólogos silenciosos de cada personaje suspendiendo brevemente el discurso. En el texto dramático se especifican estos silencios con dos palabras, siempre entre paréntesis: “(Tiempo.)”:

...el dinero es para quien lo persigue.

(Tiempo.)

¿Y tú por qué no trabajas?..." (Ídem)

O también:

Ya estoy seco pero es como si algo de esa lluvia hubiera penetrado dentro de mí. (Silencio.)

Siéntate Sandra... ¿AAcabaste el informe que te encargué?... (Rubio 2002: 18a)

Silencios solapados, que podemos imaginar cuando los personajes, ambos en silencio, están lanzándose sus pensamientos simultáneamente, provocando contrapuntos inaudibles.

"Microsilencios", en forma de puntos y seguido, puntos y aparte, puntos suspensivos, comas o respiraciones.

En definitiva, silencios múltiples, silencios sobre silencios, dentro de otros silencios que, como blanco sobre blanco llenan de matices el propio lienzo en blanco del espacio sonoro ${ }^{5}$.

5 De nuevo nos remitimos a las All White Paintings de Robert Rauschenberg e incluso a la obra de Nam June Paik, Zen for film, una película sin imágenes donde lo único que se aprecia es el polvo que se deposita en la cinta. 


\section{Silencio y otras músicas silenciosas}

En 1897, Alfons Allais escribía Marche funèbre, funérailles d’un grand homme sourd. La partitura consiste en varios pentagramas divididos en compases vacíos y podría ser el ejemplo más temprano de música silenciosa. En esa época pudo ser considerada como una broma, sin embargo, para el compositor Tom Johnson, esta pieza podría suponer un primer y rompedor paso hacia categorías estéticas musicales contemporáneas. En el prefacio de la partitura Allais escribe:

El autor de esta marcha fúnebre se inspiró en el principio universal de que los grandes dolores de esta vida son inexpresables. Puesto que son sordos, los intérpretes de esta obra deben limitarse a llevar el compás y a no hacer ruidos indecentes que destruirían el carácter solemne del mejor funeral" (AA.VV, 2001: 130).

Los intérpretes de Silencio, igualmente sordos, se limitan a llevar el compás de sus pensamientos ante la incapacidad de escucharse, cada uno a su ritmo y tempo evitando pronunciar "ruidos indecentes" que destruyan la rutinaria solemnidad de una comida de una pareja ya de por sí destruida.

El texto de Rubio también nos remite de alguna manera a la obra de Dick Higgins, A Thousand Symphonies. El papel pautado con plantilla de orquesta sinfónica y sin ninguna notación musical está perforado por disparos de pistola y enérgicas pinceladas de pintura. De nuevo el silencio se nos muestra sonoro, en este caso, violentamente sonoro, al igual que los reproches que los personajes de Silencio se lanzan en sus pensamientos, "disparándose" silenciosamente.

Por su parte, el artista austríaco Gerhard Rühm es autor de piezas musicales, visuales y también literarias. Al igual que otros artistas, también utiliza el papel pautado en su obra. En el collage Liederbilder, 1992, crea una estructura visual alternando fragmentos de partitura con otros de una fotografía en la que aparece una ciudad bombardeada y unos refugiados abandonando la zona. La fotografía ha sido seccionada de tal manera que solo aparece una persona en cada fragmento -excepto en uno de ellos en los que hay un menor acompañado-, enfatizando de esta manera el silencio, la soledad y el desgarro del momento. Igualmente la partitura está seccionada, desarticulada, imposible de ser cantada, donde solo se puede leer la palabra "Ade" (adiós).

Silencio también nos remite a una pieza del compositor italiano Walter Marchetti: Otto o nove movimenti per quartetto d'archi, 1995. Este cuarteto se interpreta al aire libre sobre una gran montaña o en un gran desierto. La distancia entre un intérprete y otro ha de ser de ocho a ocho mil metros para el primer movimiento; de siete a siete mil metros para el segundo movimiento... Como resulta evidente, cuando la distancia es de kilómetros, la incomunicación entre los intérpretes se intensifica, imposibilitando la escucha mutua y por tanto una ejecución coordinada. Los intérpretes solo se escucharán a sí mismos y sus silencios, durante los cuales probablemente están sonando otros fragmentos o quizá otros silencios. De nuevo se puede establecer un paralelismo con los personajes de Silencio, separados apenas por un metro de distancia pero incomunicados por kilómetros de reproches. La pieza de Marchetti está 
asimismo atravesada por largas pausas de silencio indicadas en números rojos sobre el pentagrama entre grupos de notas.

Otra pieza de Marchetti, Composition for eight orchestras or eight instrummental ensemble or eight organs introduce pausas silenciosas de varias horas entre fragmentos sonoros.

Podríamos citar incluso, ya en el campo de las artes visuales, instrumentos silenciosos. Es el caso de Klangtafel II, de Monika von Wedel, inspirado en la partitura December 1952, de Earle Brown. Aunque la pieza no está pensada para ser usada como instrumento musical, está atravesada por cuerdas sonoras tensadas que podrían ser activadas generando sonido

En otra línea se sitúa Yoko Ono y su libro de partituras Grapefruit. Se trata de un libro de artista publicado en 1964. En él encontramos piezas de instrucciones, dibujos, poemas, etc, que podríamos encuadrar dentro del concepto "event scores"6. Estas partituras consisten en textos a modo de instrucciones que implican la realización de acciones simples, generalmente vinculadas con algún aspecto sonoro o musical. Se pueden considerar igualmente partituras abiertas, ya que son susceptibles de varias interpretaciones o variaciones.

En Grapefruit ya encontramos piezas que, al igual que los monólogos de Silencio, se "interpretan" y se "escuchan" solo en la mente del intérprete. Es el caso de Pieza de Colección I, (1963): Coleccionar en la mente los sonidos que se han escuchado casualmente en la semana. Repetirlos mentalmente en distinto orden una tarde.

Esta pieza en particular también nos recuerda en su estructura a Intermission 6, de Feldman, comentada al principio de este escrito. Es el intérprete el que decide el orden de los eventos sonoros, convirtiéndose en parte en compositor de la pieza final.

En el caso de Pieza de Campana, (1963), Ono propone de nuevo una escucha interna a base de sonidos recordados, incorporando en esta ocasión modificaciones en la intensidad de los mismos:

Escuchar una campana durante una hora

Disminuir el sonido a piano

haciéndolo repicar en la cabeza.

Disminuir el sonido a pianissimo

haciéndolo repicar en sueños.

Disminuir el sonido poco a poco

a troppo pianissimo, olvidándolo.

Probar con otros sonidos

p. ej., voz de la madre

llanto de bebé

histeria del marido (Ono 1963)

6 Se suele atribuir la invención de las event scores al artista fluxus George Brecht. De cualquier manera, el uso de este tipo de partitura de acción se generalizó sobre todo en la década de los 60, tanto en el ámbito norteamericano -a partir de las clases que impartió John Cage en la New School for Social Research en New York- como europeo. 
Como vemos, Yoko Ono incorpora modificaciones “tímbricas” y de carácter en las variaciones propuestas al final, aún tratándose siempre de voces humanas.

Añadiremos una pieza más de Ono que nos inspira en particular, en este caso por la conexión temática con Silencio: "Pieza de bruma I / Pensar en lo que está pensando la persona de al lado" (Ibídem).

\section{Otras analogías musicales no tan silenciosas}

Como ya hemos comentado, la mayor parte de las escenas de Silencio consisten en monólogos del pensamiento y diálogos que los intersectan. Sin embargo, hay dos escenas que, simétricamente dispuestas respecto de la estructura general, funcionan de manera diferente. La segunda escena, titulada "Diálogo", consiste justo en eso, un diálogo cien por cien "sonoro" aunque inerte en cuanto que no es de relevancia para la pareja. Precisamente, dado el carácter "inútil" del mismo, Sergio Rubio propone un juego contrapuntístico muy interesante a base de preguntas y respuestas cortas en las que la imitación, a veces literal y a veces libre, dotan al texto de una agilidad rítmica que contrasta con el ritmo lento de la primera escena:

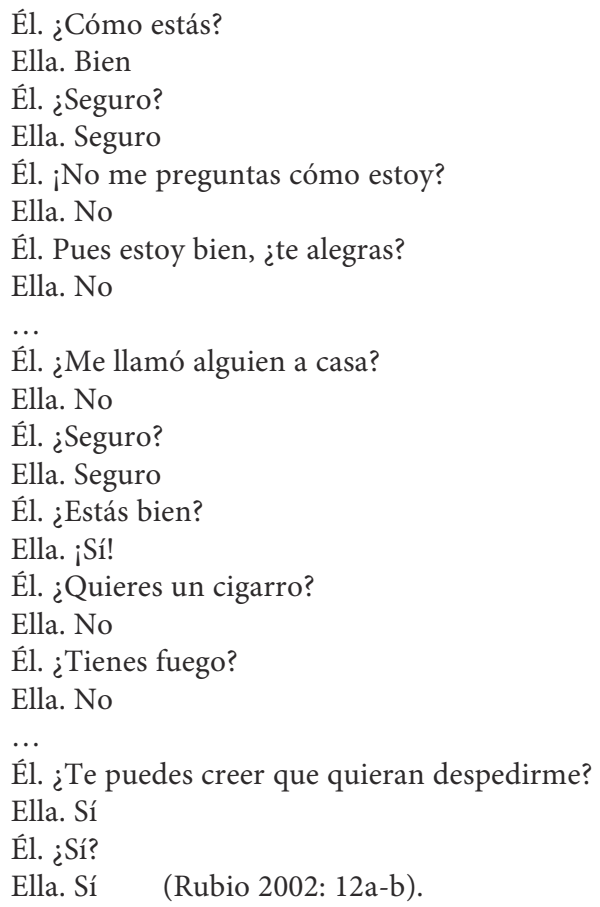

La repetición de palabras como "seguro", "bien”, “si”, o "no" nos remite al recurso compositivo de la imitación, ya que aparecen repartidas por toda la escena en diferentes contextos, aportando dinamismo y a su vez, unidad. Igualmente ocurre más avanzada la escena con otras palabras como "nada", 
"diamantes" o "pena", que se suman en un contrapunto más complejo a las primeras palabras repetidas. Por otra parte, los monosílabos como respuesta aceleran el desarrollo rítmico del texto, provocando cambios de velocidad que de nuevo contrastan con el resto de las escenas. Curiosamente en esta escena, quizá la más rítmica, se hace referencia a un reloj, un reloj que Ella no lleva puesto asegura que lo perdió- pero tampoco quiere tener.

La quinta escena, "Ecos", merece sin embargo un enfoque diferente. Rubio de nuevo recurre al recurso de la imitación, aunque de una forma distinta a la segunda escena, más discreta. De hecho solo la utiliza al comienzo de la misma. Sin embargo lo que caracteriza a esta escena es la aparición de un componente distinto, un nuevo "oyente" entra en escena. La forma verbal que ahora emplean los personajes nos descubre que éstos lanzan sus palabras hacia otro ente que ya no es su pareja, sino posiblemente hacia el público, que bien puede ser el de la sala de la representación o cualquier otro. Por primera vez aparece otro foco, otro oído receptor distinto de ellos mismos, al cual dirigen sus explicaciones y justificaciones, de nuevo sin recibir respuesta. El espacio sonoro se expande, se amplifica. Como si de un muro se tratase, los personajes lanzan sus afirmaciones hacia un público esperando quizá que encuentren algún eco, reforzándose a sí mismas al pronunciarlas en voz alta, como ocurre según la física del sonido. El texto abunda en esta idea de eco, en particular al inicio de la escena donde las frases de cada personaje son repetidas por el otro. Sin embargo, en este caso Sergio Rubio utiliza una repetición que no es del todo exacta, lo que nos da pie a considerar otro recurso compositivo interesante que es la heterofonía. Esta consiste en la interpretación simultánea a varias voces de una misma melodía, que aparece variada en algún aspecto generando una textura muy particular ${ }^{7}$. Cabe entonces plantear al menos dos posibles interpretaciones del texto desde el punto de vista musical. Si los textos de los personajes se interpretan de forma consecutiva se reforzaría la idea de imitación en forma de eco. Si se interpretan de forma simultánea superponiendo las frases de Él y Ella se producirá entonces el efecto heterofónico -presuponiendo los inevitables desfases que, en este caso favorecerán dicha textura-. Conforme avanza el texto la heterofonía va desapareciendo, ya que las variaciones de las frases son cada vez más evidentes. Sin embargo, hacia el final y de repente, confluyen en un unísono:

Ella. Le quería les juro que le quería

Él. La quería puedo jurarles que lo hacía

Ella. Hace tiempo...

Él. Hace mucho tiempo.

Ella. Para mí no existía nadie más que él

Él. Eh... No había nadie más en mi vida.

Ella. Lo dejé todo por quererle más, por estar más cerca suya.

7 Tal textura puede ser considerada como una variedad de monofonía compleja en la que solo hay una melodía básica, pero es interpretada simultáneamente por múltiples voces, cada una de las cuales ejecuta la melodía de una forma diferente, ya sea con distintos adornos melódicos, o bien ritmos o tempo diferentes. 
Él. Comencé a trabajar para proporcionarle más comodidad.

Ella. No hacía más que esperarlo todos los días como...

ÉL. Como una de esas historias antiguas donde la mujer se sienta...

Ella. Observando el mar.

Él. Observando el mar (Rubio 2002: 17a).

El efecto heterofónico "sonoro" con el que se inicia se va disipando conforme avanza la escena. Sin embargo, encontramos de nuevo una analogía musical en lo que a temática se refiere. A partir del unísono, los personajes comienzan a mostrar sus puntos de vista sobre asuntos comunes pero con posturas cada vez más alejadas entre sí. Volvemos de nuevo a una textura contrapuntística que se interpreta ahora desde registros muy alejados, como instrumentos cuyos timbres son incapaces de empastar.

Y tras aparecer el tema de los hijos, las diferencias se acentúan aún más. Ya no aparecen imitaciones, ni ecos, ni heterofonías, ni temáticas similares. Mientras que la intervención de Él se estanca en una temática irrelevante, la de Ella se torna profundamente dramática, provocando un juego contrapuntístico que evoluciona "por movimiento contrario"8.

La última escena ("Postres") culmina con un diálogo a modo de "coda"9, donde resuenan de nuevo las palabras y monosílabos del diálogo de la segunda escena. Parece que todo sigue igual, sin embargo, ha dejado de llover... Quizá ahora se escucha aún más el Silencio.

\section{Bibliografía}

AA.VV., 2001, Minimalismos, un siglo de los tiempos, Madrid, Museo Nacional Centro de Arte Reina Sofía.

Ariza J., 2003, Las imágenes del sonido, Cuenca, Ediciones de la Universidad de Catilla-La Mancha, "Colección Monografías".

Cage J., 2002, Silencio, Madrid, Árdora.

Johnson S., 2002, The New York Schools of Music and Visual Arts, New York, Routledge.

Kühn C., 2003, Historia de la composición musical en ejemplos comentados, Barcelona, Idea Books.

Ono Y., 1970, Pomelo, Buenos Aires, Ediciones de la Flor, <https://monoskop. org/images/8/83/Ono_Yoko_Pomelo_Un_libro_de_instrucciones_de_ Yoko_Ono.pdf>.

8 Concepto referido a la marcha armónica de las voces, cuando éstas se mueven en direcciones opuestas.

9 Es una sección musical al final de un movimiento, a modo de epílogo. Técnicamente se trata de una cadencia expandida. Con lo cual, puede ser tan simple como unos pocos compases o alcanzar tal complejidad que constituya una sección entera. 
Pardo Salgado C., 2001, La escucha oblicua: una invitación a John Cage, Valencia, Editorial Universidad Politécnica de Valencia, col. "Letras Humanas".

Pritchett J., 1996, The music of John Cage, London, Cambridge University Press.

Rubio, S., 2002, Silencio, en: Rubio, S., Samper, M. y Gutiérrez, P., Silencio / 405 / Carne de cerdo, Sevilla, Centro Andaluz de Teatro y Centro de Documentación de las Artes Escénicas de Andalucía, col. "Premio Miguel Romero Esteo" no 2, p. 7-19. 